\title{
RESEARCH AND TESTING OF FUEL OIL COMBUSTION, USING FLAME INFRARED THERMOGRAPHY
}

\author{
by Victor V. Ghiea (Ghia)
}

Polytechnic University of Bucharest, Thermo-Mechanical Engineering Dep., 313 Spl. Independentei, Sector 6, Bucharest, Romania, E-mail: ghiea_victor@yahoo.co.uk

\begin{abstract}
Was analyzed the influence of simulator mini-furnace initial inner temperature on fuel oil droplet $(F O D)$ combustion development, establishing the combustion physical model for flame infrared thermography (FIRT) use. An FIRT original method for research-testing $(R T)$ of a burning $F O D$ is obtained, giving valuable data on the diffusion combustion process development, and new criteria for determination of gas oils $(G O)$ combustion quality. Also resulted a graphologyc - thermographyc method for RT of FOD combustion, founded on imagining processing of obtained experimental results, by combustion oscillogram (COS) and flame infrared thermogram (FIT). Interpreting the COS supported by FIT diverse profitable industrial activities were presented.
\end{abstract}

\section{1 , Introduction}

The main fuel oils for industrial use are considered: heavy (HFO) and intermediate fuel oil (IFO) together with GO. HFO, IFO and in general inferior fuel oil (IFO), especially are produced by mixing in different proportions of the residues obtained from crude petroleum treatment (atmospherically distillation, vacuum distillation, thermal cracking, catalyst cracking...etc.) and light products. Generally speaking as IFo are considered HFO and inferior IFO. Infrared Thermography (IT) for droplet combustion research uses the accumulated experience by the research and particularly advantageous applications of fuel oil droplet combustion graphology [1] which concerns especially with the graphic transposition for $R T$ of $F O D$ combustion processes. Thus, using a combustion simulator (Fig.1), experimentally are established the radiation-combustion-ignition characteristics $(R C / C)$, also including the laws that govern their changes, depending on created combustion conditions and fuel oil quality. By scientific interpretation of experimentally obtained $R C / C$, were applied economic proceedings for improvement of fuel oil (FO) quality as: additivetion, mixing of a low grade fuel oil with a compatible light oil, physicmechanical treatment and chemical treatment to eliminate the content of sulphur or other polluting components. Also was possible an economically improving of many industrial combustion processes as for examples are: combustion of water-in heavy fuel oil emulsion (CWHFE), combustion with additived air (CAA) for ionization of combustion furnace volume, or combustion utilizing ultrasonic disturbances for high gas-turbulence process. Similar as fuel oil combustion graphology, we can create and develop the droplet combustion thermography [2], which at the beginning is used for combustion $R T$ of $F O D$ flame. These are founded on imagining experimental results by infrared thermograms according to the measured apparent 
temperature $\left(T_{a}\right)$. In the first stage this activity especially represents an important scientific-technical support for combustion graphology and GO characterization.

\section{FO combustion physical model, for FIRT method use}

For a scientific solution, at the beginning was established the thermal pßyver ( variation of heat exchange by radiation between a $F O$ droplet and the incandescent wall of a simulator tubular mini-furnace in combustion and ignition development. During the time of droplet existence $t_{e}$ for an IFo droplet $t_{e}=t_{i}+t_{v}+t_{c}$, [1], the function $P$ has an important variation [Fig.2]. The self-ignition delay $t_{i}$ is the time elapsed from droplet introduction in the center of mini-furnace till droplet ignition (which is distinguished in the same time by flame appearance). Combustion time of the volatile matters (flame) $t_{v}$ is the time elapsed from droplet ignition till flame extinction. Cenosphere $(\mathrm{Ce})$ ignition delay $\Delta t$ (when practically exist) is the time elapsed from flame extinction till the visible ignition of the Ce. The combustion time $t_{c}$ of $\mathrm{Ce}$, was defined as the interval of time elapsed between the extinction of the flame and $\mathrm{Ce}$ extinction. Indeed, the $P$ thermal power of radiation heat exchange between wall and burning droplet or vice versa, has a variation in time $t$, which can be represented in a rectangular system of axes $P O t$, with $t$ for abscissa and $P$ on ordinate. For the $t_{i}$ time (segment $\mathrm{Oa}$ on $\mathrm{Ot}$ axe), the variation curve $P=f(t)$ shows a very slow decreasing only due the droplet heating. In the $t_{v}$ (segment ac), $t_{c}$ (segment $\mathrm{ce}$ ) interval of times, aspect of heat exchange formula become more complex due the heat exchange between droplet flame or $\mathrm{Ce}$ variable in time, and the incandescent wall. After the appearance of droplet flame (point a on Ot axe), in _t $t_{a b}$ time interval (b being the intersection between $P=f(t)$ curve and $O t$ axe), the flame receives heat from incandescent combustion chamber wall, but in approximate $t_{b c}=t_{v}-{ }_{-a b}$ time interval, the flame having a temperature larger as the incandescent wall, gives up heat to wall. In the graphic representation, is admitted that $\mathrm{Ce}$ in the point $\mathrm{c}$, has an inferior temperature of the wall and for ignition. The Ce ignites visible in the point $\mathrm{d}$ after the passing of $t$ cenosphere ignition delay time, and in $t_{c}$ time receives heat from hot wall. In this interval of time the curve $P(t)$ decrease especially due two effects determined by: carbon combustion yielding heat of $\mathrm{Ce}$ decreasing by time passing and $\mathrm{Ce}$ incandescent surface decreasing in combustion process development, which decreases the received heat from incandescent wall. This droplet combustion physical model (DCPM) changes a little when the droplet flame temperature has a high value permitting to the $\mathrm{Ce}$ carbon rapidly to ignite, so that $t$ is negligeable and ordinary miss. As a result of these phenomena, the infrared thermograms of the burning fuel oil $(F O)$ droplet will give $T_{a}$ apparent temperatures, larger in intervals of times $t_{a b}, t_{c e}$ and lower in intervals of time $t_{b c}$, in comparison with the real possibilities of the tested fuel. Indeed, when the burning droplet receives heat from incandescent wall, a part of this heat is absorbs and reflects, thus increasing the radiated energy towards the detector of infrared camera (IRC). Realizing the $T_{e}$ environmental air temperature for inner of simulator mini-furnace is accomplished the main condition to obtain $F I T$ for real quality of experimented $F O$, but is not possible to ignite and burn $\mathrm{Ce}$, only from droplet flame released energy. This DCPM which will be used at thermographyc experiments differs of DCPM above presented, and also differs the used combustion simulators. for $R T$.

\section{FIRT method for research and testing of $F O$ droplet combustion}

The used simulator with an un-heated combustion chamber permits the burning at $T_{e}$ temperature of individual fuel oil droplets, with the initial mean diameter $d_{0}$ having 
temperature $T_{0}$, but using a special droplet igniter. For experiments was used an improved $I R C$, operating in the wavelenght infrared band $\Delta \lambda=3.4-5 \mu \mathrm{m}$, in order to obtain the FIT with thermal images. This FIT gives the fields of apparent temperatures $T_{a}$ of burning droplet at a real - time of the combustion process development. The values of $T_{a}$ are function especially of: $d_{0}$ diameter , $t$ time and FO characteristics. These characteristics establish the combustion droplet fuel quality which determine the droplet combustion process development with droplet flame $T_{a}$ for his emissivity $\varepsilon$. From the FIT initial analyze has resulted that for a given $F O$ the apparent temperatures are greater when $d_{0}$ is greater and the $t$ time is nearer of value corresponding to the droplet flame maximum volume (DFMV), which is the reference value. Using an appropriate $I R C$, the mean real temperature $T_{r}$ corresponding to $T_{a}$, can significant characterize the $F O$ combustion process development. But $T_{r}$ temperature results when is know the emissivity $\varepsilon$ in direction of normal incidence of Fig. 3 referring to $x A y$ plane, within the $\Delta \lambda$ band. The initial droplet symmetry center is specified by point $A$. Theory and practical experience show that in the majority of $F I T$ points for droplet flame, the emissivity $\varepsilon$ is sensible variable in function of numerous parameters. These are especially: concentration in flame of soot fine particles (which is the most important parameter), content of $\mathrm{CO}_{2}$ and $\mathrm{H}_{2} \mathrm{O}$ gases which are released in combustion process, gaseous layer thickness and temperature of gases. But these parameters are variable in the time of droplet burning. For this reason it is impossible to determine with precision, even by special methods, the variable value of $\varepsilon$. In laminar diffusion flames, the soot forms on fuel rich side of the reaction droplet envelope appeared due the burning of yielded volatiles matters. Soot oxidizes as it diffuses into the hot reaction zone. Since the supply rate of soot is increased permanently not all of the soot can be oxidized. The soot that is not oxidized escapes from the tip of flame. To obtain a small variation of $\varepsilon$ in normal direction at $x^{\prime} x$ axe, for the interval of burning droplet liquid, with a reduce difference between $T_{a}$ and $T_{r}$, it is necessary to burn in ambient air relative large droplet releasing abundant soot by diffusion combustion and the environment giving a very low emissivity.. Thus, the released fine particles of soot are rich and spectral emissivity $\varepsilon(\lambda)$ varies slowly with wavelenght $\lambda$, for some droplet flame zones, similar as for solid objects. In normal direction to xAy plane surface for the point $A$, where the released soot is larger, and the liquid droplet represent a background screen, the emissivity $\varepsilon$ for an industrial fuel oil in diffusion combustion, has a great value which can approach to blackbody emissivity. Apparent temperature $T_{A}$ for the point $A$ is computed according to radiation energy of the referent flame layer thickness with abundant soot, and the burning fuel oil droplet liquid. In direction from droplet towards the droplet flame ended, the emissivity decreases especially due soot concentration and gaseous layer thickness decrease, but increases with temperature diminution. Such as, if we admit $\varepsilon=0.9$, for which in FIT the temperature $T_{A}$ is determined, but in reality $\varepsilon$ decreases with 0.2 till a point of flame significant considered, in this point results $T_{r}=1.0648 T_{a}$. Indeed $I R C$ can automatically realizes the correction for emissivity $\varepsilon$, but for the whole $I T$. Thus for $\varepsilon_{1}$ the apparent temperature is $T_{a 1}$, and for $\varepsilon_{2}$ the apparent temperature $T_{a 2}=\left(\varepsilon_{1} / \varepsilon_{2}\right)^{0.25} T_{a 1}$, but the influence of $\varepsilon$ variation is much less important as temperature $T_{a}$ variation in the validity field of Stephan Boltzmann's law. For this reason, the analysis and comparison of $T_{a}$ temperature fields from $F I T$, according to $\varepsilon$ estimation give valuable qualitative informations on diffusion combustion process development, very dependent on $T_{r}$ temperature. Also by use of the proposed method, analyzing FIT obtained by experiments performed in the same initial combustion conditions of droplets, for a tested $F O$, and a standard $F O$, new criteria of the fuel combustion 
quality determination, can be established. Thus to characterize and compare, the GO combustion quality at $D F M V$, where defined criteria: $T_{m x}$ - average of flame apparent temperatures in normal direction on the $x x$ axe and $x A y$ plane, $\left[{ }^{\circ} C\right] ; T_{t}$ - average of total flame apparent temperatures in normal direction on $x A y$ plane, obtained by conversion of total radiation energy in $\Delta \lambda$ band, from the burning droplet, $\left[{ }^{\circ} \mathrm{C}\right] ; T_{A}-$ apparent temperature in normal direction on the $x A y$ plane, for the point $A,\left[{ }^{\circ} \mathrm{C}\right]$. Also can be established secondary qualitative selection criteria in connection with the shape of curves for apparent temperature corresponding to $x x^{\prime}$ and $y y^{\prime}$ axes, namely $T_{a x}=f(x)$ and $T_{a y}=F(y)$. Experimental researches and testings, were effected using the presented combustion simulator, with different types of GO and IFO, in the same initial conditions, characterized by: temperature of environmental combustion air $T_{e}$ and $F O$ temperaturel $T_{0}$; natural draft for combustion air feeding; cylindrical uncooled combustion chamber; and initial mean diameter of droplet $d_{o}$. It was necessary the realization of a special device for precise droplet calibration at diameter $d_{0}$ to obtain the same fuel volume for every type of FO. As examples of FIT are presented Fig.4, and Fig.5. The range of $T_{a}$ measured temperature for the used $I R C$ was limited in two distinctly intervals of temperature variation $\left(0-450{ }^{\circ} \mathrm{C}\right.$ and 450 - $2000{ }^{\circ} \mathrm{C}$ using an optical filter of the burning droplet radiations). During the majority of fuel oil testings, variation of above mentioned criteria, for $\varepsilon=1$, was: $T_{m x}=295$ $357{ }^{\circ} \mathrm{C} ; T_{A}=387-447{ }^{\circ} \mathrm{C}$ and $T_{t}=263-293{ }^{\circ} \mathrm{C}$. The conclusion of numerous experiments and according theory shows that when the $\mathrm{GO}$ combustion quality is better, the criteria $T_{m x}, T_{A}$ and $T_{t}$ have larger values. In general, these criteria have decreased values for a low GO in comparison with a superior GO. For IFO and HFO, the droplet burning time with flame is represented by $t_{v}$ and after this time following the Ce burning time $t_{c}$, and together with ignition delay time $t_{i}$, which also characterize the fuel quality. These characteristics easily are obtained by a graphologyc method. In general, the graphologyc $R C I C$ results from the interpretation of the COS.

\section{RCIC, combustion graphology method supported by FIRT method}

The main $R C I C$ result from COS, which is a graphic transposition of the ignition and combustion of a $F O$ droplet into a simulator mini-furnace [Fig.1]. The experimental results are obtained in standard conditions, and show on a computer display as a curve represented in coordinates of axes of a rectangular system (Fig.2). The $t$ time variation is represented on the abscissa and the $I$ radiation intensity variation of the burned droplet on the ordinate. The radiation is transformed in electric signals as voltage (I) or electric power $(\Phi)$ through a photocell with amplification. The standard conditions are mainly specified by: the geometry of the combustion chamber; the initial temperature $T_{f o}$ and the pressure $p_{0}$ inside the combustion chamber which in the usual variant is approximately equal to the atmospheric pressure; the environmental temperature $T_{\mathrm{e}}$ and $F O$ temperature $T_{0}$; the system of supporting and inserting the droplet inside the incandescent combustion chamber; the air flow conditions arrowed the droplet, mainly characterized by the value of the Reynolds number $R e$; the mean initial diameter $d_{0}$ of the combusted droplet. The application of the combustion testing method is based upon the oscillogram curve and display of measured and calculated dates, which are obtained using the above presented simulator. For an IFo droplet insert inside the combustion chamber where ignition and combustion takes place is possible to measure the main $R C I C: t_{\mathrm{i}}, t_{\mathrm{v}}, \Delta t, t_{\mathrm{c}}$, flame radiated energy transformed by the photocell into electric energy at the burning of the volatile maters $E_{v}$, energy radiated by burning $\mathrm{Ce}$, transformed by the photocell into electric energy $E_{c}$; maximum radiation intensity obtained at the burning 
of the volatile maters $I_{v}^{m}$ or of the cenosphere $I_{c}^{m}$. The droplet existence time is $t_{\mathrm{e}}=$ $t_{\mathrm{i}}+t_{\mathrm{w}}$ depends of whole combustion time $t_{\mathrm{w}}=t_{\mathrm{v}}+t_{\mathrm{c}}$

In order to make a determination, on combustion simulator, the following steps are to be taken: creation of the $d_{0}$ initial mean diameter droplet desired and obtained at the extremity of the syringe needle, through the controlled translation of a piston using a specialized screw mechanism; verification through direct measurement with a specialized interpolated microscope of the mean diameter $d_{0}$; to enter and store in the computer's memory the value of the parameters $T_{f i}$ (incandescent mini-furnace inner temperature), $T_{\mathrm{e}}, T_{\mathrm{o}}, d_{\mathrm{o}}$, the $F O$ density and appreciated maximal time of the combustion process development; insertion of the droplet inside the combustion chamber to be simultaneous with initiating data acquisition and storing system; ignition and combustion of the droplet; displaying of the combustion oscillogram on the computer's display; establishment of the $t_{\mathrm{i}}, t_{\mathrm{v}}$ and $t_{\mathrm{c}}$ times, which is done by exploring the combustion oscillogram; introduction into the computer's memory the processed and tabulated experimental results and the resulted combustion oscillogram. For two grade (superior and inferior) of IFO droplets having the same $d_{o}$, which are ignited and burned in mini-furnace of simulator at the same initial conditions $T_{\mathrm{fi}}, T_{\mathrm{e}}, T_{\mathrm{o}}, p_{\mathrm{o}}$, and $R e$, \{when the low IFO or GO has the RCIC noted with index 0 ), for the majority of cases are accomplished the main conditions :

$$
t_{\mathrm{i}}<t_{\mathrm{io}}, t_{\mathrm{vo}}<t_{\mathrm{v}}, t_{\mathrm{co}}>t_{\mathrm{c}}, I_{v}^{m}>I_{v o}^{m} \text { and } I_{c o}^{m}>I_{c}^{m}
$$

The point M in Fig.2 establish the time for DFMV where FIRT method can give useful details on $T_{f}$ values and repartition of these temperatures in the IRT. In cases of GO and vegetable oils $t_{w}=t_{v}$ because $t_{c}=0$ and so miss the curve of $t_{c}$ variation $I_{c}=F(t)$. The low GO has the times $t_{i}$ and $t_{v}$ increased, by comparison with superior and usual $G O$. Thus are accomplished the main graphologyc and thermographyc conditions:

$$
t_{\mathrm{i}}<t_{\mathrm{io}}, t_{\mathrm{vo}}<t_{\mathrm{v}}, I_{v}^{m}>I_{v o}^{m}, T_{A o}<T_{A}, T_{t o}<T_{t}, T_{m \times o}<T_{m x}
$$

For this reason also it appears useful to improve their quality by mixture with compatible light oils or by additive. Often the main objective is to decrease the selfignition delay $t_{\mathrm{i}}$ of low gas oils in order to increase the certain index. The determination on simulator of the $t_{\mathrm{i}}$ time using combustion oscillogram for different possible solutions, give the optimum solution for minimum amount of the self-ignition delay time. When it is necessary to use a substitution oil as a vegetable oil or improved mixture fuel, first of all must be also obtained the combustion oscillogram for the new fuel, which must be similar which the combustion oscillogram of a GO having a good behavior on diesel engine.. As a result it is possible with minimum modification to use alternative fuels and to develop the means of converting them so that a given $F O$ can be replaced or supplemented with another more available $F O$.

In case of CAA [2] of inferior fuel oil at boilers for environment pollution decrease and fuel savings increase, due the combustion heat release into the boiler furnace, the solid particles of additive from the combustion air becoming aerosols decompose and give atoms of free oxygen. A part of the formed ions is transported by thermophorese towards the cold inner walls of boiler, where react with existent carbon in soot deposits on the furnace heat transfer surfaces, becoming easy friable deposits. At the bottom, in air with activated aerosols will be develop two ionization components, having advantageous effects. Thus the released free oxygen having negative charge determine the acceleration of approaching between $\mathrm{O}_{2}$ and 
hydrocarbons, resulting a faster combustion reaction with a flame shorter as closer, and the molecular aerosols with negative charge acting on the chains of hydrocarbons favoring their breaking off and reducing the necessary combustion energy. The ionization effect propagates in the whole combustion chamber and taking into account of the temperature simultaneously increase, is obtained favorable conditions for combustion process intensification with complete combustion and decrease of environmental pollution. For this reason, first of all it is necessary to know the optimum quality and quantity of additives becoming aerosols, which in fuel combustion air will be added. A good additive for the combustion process intensification must accomplish the following main conditions: chain reactions in furnace due the air oxygen to quickly decompose his molecules in atoms; production by decomposition of a large quantity of free atomic even at relative low temperatures in furnaces; to give a great friability for the fine solid particle deposits formed on heat transfer surfaces or to permit the mixing with an other adequate additive; to have a good solubility in water and therefore to give easy the liquid aerosols; preservation of the advantageous characteristics at ambient temperature for the resulted electrolytic watery solution; does not be toxic and it does not give pollutant products of decomposition; does not be corrosive itself and his decomposition products; does not be explosive at the operation normal conditions and to be cheap and available. All these conditions are not possible to be simultaneously accomplished at a single additive. For this reason the optimal additive is a mixing among different substances as bichromates and chromates of potassium or sodium, derivates of nitric acid ... etc., these mixtures being patented. As an example, are the combustion oscillograms of Fig. 6 for a droplet of HFO no. 5 about ASTM 396, burned with and without additived air at the initial standard conditions $\left(T_{\text {if }}=1023 \mathrm{~K}, T_{o}=300 \mathrm{~K}, T_{e}=293 \mathrm{~K}\right.$, $\left.d_{0}=1.8 \mathrm{~mm}, \operatorname{Re}=135\right)$ give: $t_{i a}=194 \mathrm{~ms}=0.83 \mathrm{t}_{\mathrm{i}}, t_{v a}=1398 \mathrm{~ms} \approx t_{v}, t_{c a}=2400 \mathrm{~ms}=1.28 t_{c}$, $I_{v a}^{m}=1.023 I_{v}^{m}$ and $I_{c a}^{m}=1.54 I_{c}^{m}$. The electrolytic watery solution contained especially $0.5 \% \quad \mathrm{~K}_{2} \mathrm{CrO}_{4}$ additive, but the air containing additived aerosols represented $1 \%$ of the used total combustion air. The points $M_{a}$ and $M_{v}$ establish the times for DFMV where FIRT method give useful details on $\mathrm{T}_{\mathrm{f}}$ values and repartition of these temperatures in the IRT. Using the same presented combustion testing method, for the case of combustion with additived aerosols we obtain the main $R C I C$,

as $t_{i a,}, t_{v a}, t_{c a}, I_{v a}^{m}, I_{c a}^{m}, S_{v a}$ and $S_{c a}$, with ${ }_{-}=t_{c a^{-}} t_{a}$ (when exist $\Delta t_{a}$ ), we have:

$$
S_{c a}=\int_{0}^{\theta} I_{c a} d t=\int_{0}^{\theta} F_{a}(t) d t \quad(3) \text { and } \quad S_{v a}=\int_{0}^{t v a} I_{v a} d t=\int_{0}^{t_{v a}} f_{a}(t) d t
$$

The function $l_{a}$ and $\Phi_{a}$ give integrated values for a spectral band interval $\lambda_{1} \div \lambda_{2}$ of

the photocell absorption. Only if the sensibility of the photocell $\xi_{a}=d l_{a} / d \Phi_{a}$ is considered constant, results:

$$
\begin{aligned}
& S_{c a}=\xi_{a} E_{c a}=\xi_{a} \int_{0}^{\theta} \Phi_{c a} d t \quad(5) \text { and } S_{v a}=\xi_{a} E_{v a}=\xi_{a} \int_{0}^{t v a} \Phi_{v a} d t \\
& \text { having } \Phi=\int_{\lambda_{2}}^{\lambda_{1}} \Phi_{\lambda}(\lambda) d \lambda
\end{aligned}
$$


Where $\Phi_{\lambda}(\lambda)$ is the radiant power for $\lambda$ wavelength, having $\lambda_{1}=0.35 \mu \mathrm{m}$ and $\lambda_{2}=1.3 \mu \mathrm{m}$ according the used simulator photocell. For the combustion without additived aerosols the main $R C I C$ are: $t_{i}, t_{v}, t_{c}, I_{v}^{m}, I_{c}^{m}, S_{v}$ and $S_{c}$. The functions $S_{c}$ and $S_{v}$, with the same meaning as $S_{c a}$ and $S_{v a}$, result from similarly relations as where presented. Effecting numerous experiments, resulted that for an industrial more efficient additive it is necessary to be simultaneously accomplish the conditions:

$$
\begin{aligned}
& t_{i a}<t_{i} ; t_{v a} \cong t_{v} ; t_{c a_{-}} t_{c} \\
& I_{v a}^{m}>I_{v}^{m} ; I_{c a}^{m}>I_{c}^{m} ; S_{v a}>S_{v} ; S_{c a}>S_{c}
\end{aligned}
$$

When appear more solution, the best solution correspond to the maximum values for $I_{v a}^{m}, I_{c a}^{m}, S_{c a}, S_{v a}$ and $T_{a}$ temperatures in IRT for DFMV determined by $T_{\text {Aoa, }} T_{t \text { a }}$, $T_{m x}$, together with minimum values for $t_{c a}$, $t_{i a}$, times. These are new scientifically criteria to select the variants of additivetion, which will be supplied to the boiler, for the optimal solution establishing. Thus the experiment effectuated on simulators can improve the combustion with activated aerosols and in different other cases, thus much will be reduce the expensive industrial costs of experiments.

\section{Conclusions}

FO droplet flame infrared thermography represents an important part of combustion thermography, which can be developed in the future especially referring to the cenosphere combustion and radiation. The FIRT proposed method of FO droplet combustion, open a new field of activity which improves the knowledges of $F O$ volatile matters combustion processes. But is established a droplet combustion physical model for fruitful $R T$ experiments and referring to $G O$ are given already new criteria for their quality determination. There is a certain similitude between $F O$ combustion graphology and $F O$ combustion thermography especially referring to the use of droplet burning radiation transformed in electrical signals for combustion processes characterization through a graphic representation as COS and FIT. According these graphic representations the detector of burning droplet radiations operates in different wavelength and have different degrees of construction complexity. In this development stage of miniaturized $F O$ combustion for research and testing, the combustion thermography method appear as an useful complement for the combustion graphology method permitting to realize a complex gaphologycthermographyc method. By the use of this proposed combustion $R T$ method, it is possible also to be carried out different other very economical applications. Thus, is resulted the economic optimization of HFO and IFO symbiotic combustion technologies for reducing environmental pollution and obtaining fuel savings; by predicting the advantageous industrial solutions and avoiding many expensive industrial experiments, as for example are the CWHFE and CAA. Indeed, applying combustion of CWHFE at $330 \mathrm{t} / \mathrm{h}$ power boilers [3], gave numerous advantages, as: for the boiler gross thermal efficiency $\eta=92.6-93.5 \%$ with a water content of emulsions $W \cong 9.5 \%$ resulted the increase of $\eta$ of minimum $1.5 \%$; great diminution of soot and oil coke particles deposits on the convective heating surfaces; depollution of the environment due especially unburned solid particles; increase of the operation time between boiler stoppings. Also by applying CAA at a power boiler of $420 \mathrm{t} / \mathrm{h}$ steam was resulted the $\eta$ increase with about $1.5 \%$, especially due the reduction of solid fine particle deposits on the heat transfer surfaces, which become easy friable 
and an important decrease of the environmental pollution by emission of solid particles and $\mathrm{NO}_{x}$ concentration in exhaust gases, together with other advantages.

KEYWORDS: Infrared thermography, combustion graphology, energy savings, research, boiler applications

\section{Nomenclature}

$R C I C$ - radiation combustion ignition characteristics; FIRT - flame infrared thermography; CWHFE - combustion of water - in heavy fuel oil emulsion; DFMV droplet flame maximum volume; IRC - infrared camera; ITH - infrared thermography; CAA combustion with additived air; HFO - heavy fuel oil; FIT - flame infrared thermogram; $R T$ - research and testing; a - index concerning $C A A$; o - index concerning low IFO or GO; $\mathrm{Ce}$ - cenosphere; $t$ - time variation, [ms]; I - radiation intensity of the burning droplet converted by photocell into voltage, [mV] or into electric power as $\Phi[\mathrm{mW}] ; t_{l}$ - self-ignition delay time, $[\mathrm{ms}] ; t_{\mathrm{v}}$ - combustion time of volatile matters, $[\mathrm{ms}] ; t_{c}$ - combustion time of cenosphere, [ms]; $d_{0}$ - initial mean diameter of droplet, [mm]; _ - wavelenght, [ $[\mathrm{m}] ; E_{v}, E_{c}$ - energies radiated by the flame and $\mathrm{Ce}$ of burning droplet, transformed by photocell into electric energy, [ $\mathrm{mJ}$; $T_{f i}$ - initial temperature inner the mini-furnace of simulator, $[K] ; T_{e}, T_{0}-$ environmental air and fuel oil temperatures, $[K] ; T_{a}, T_{r}$ - apparent and real temperatures, $\left[{ }_{1}\right] ; T_{m x}$, $T_{t}$ - average of apparent temperatures, on $x x^{\prime}$ axe and total flame, [YC];

\section{REFERENCES}

[1] Ghia V.V. Efficient application of a graphologyc method for fuel oil. Proceedings of the $5^{\text {th }}$ AITA (2000), Venezia, CNRS, p.41-48.

[2] Ghia V.V.and C. Dumitra_cu, Method using infrared thermography for combustion testing of fuel oil., Rev.Roum.Sci.Téchn. Électrotechn. et Énerg.,47(2002), nr.2, p.219 - 228.

[3] Radulescu, M., Technologies for improving combustion processes of heavy fuel oils. Energetica, Serial A, 47(1999), nr.7, p. 297-308.
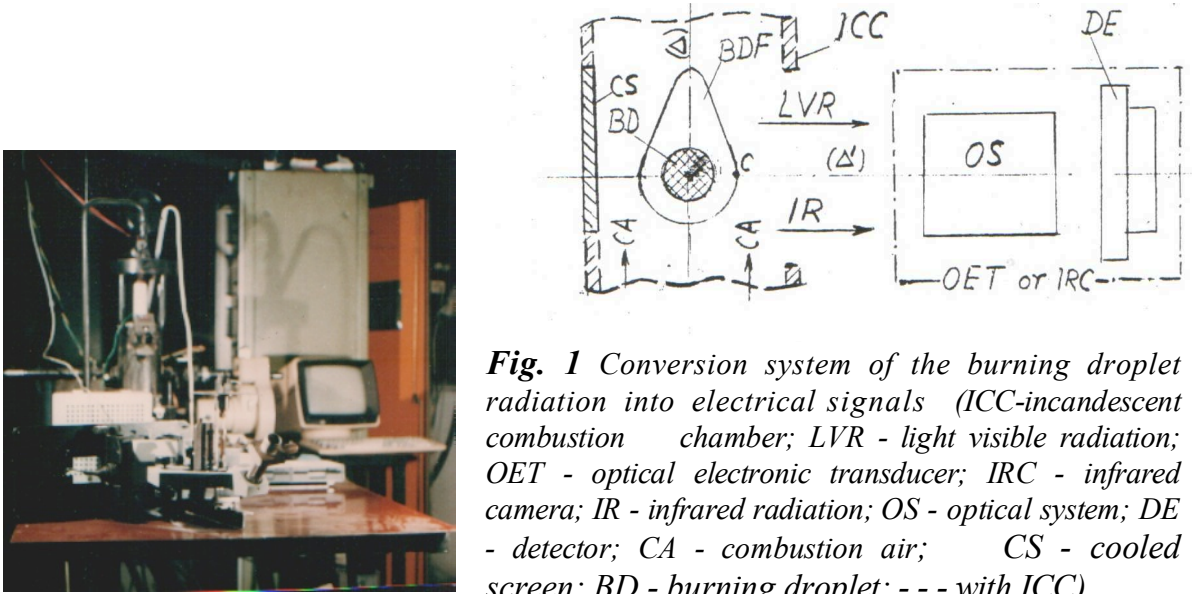

Fig. 1 Conversion system of the burning droplet radiation into electrical signals (ICC-incandescent combustion chamber; LVR - light visible radiation; OET - optical electronic transducer; IRC - infrared camera; IR - infrared radiation; OS - optical system; $D E$ - detector; CA - combustion air; CS - cooled screen; BD - burning droplet; - - - with ICC) 


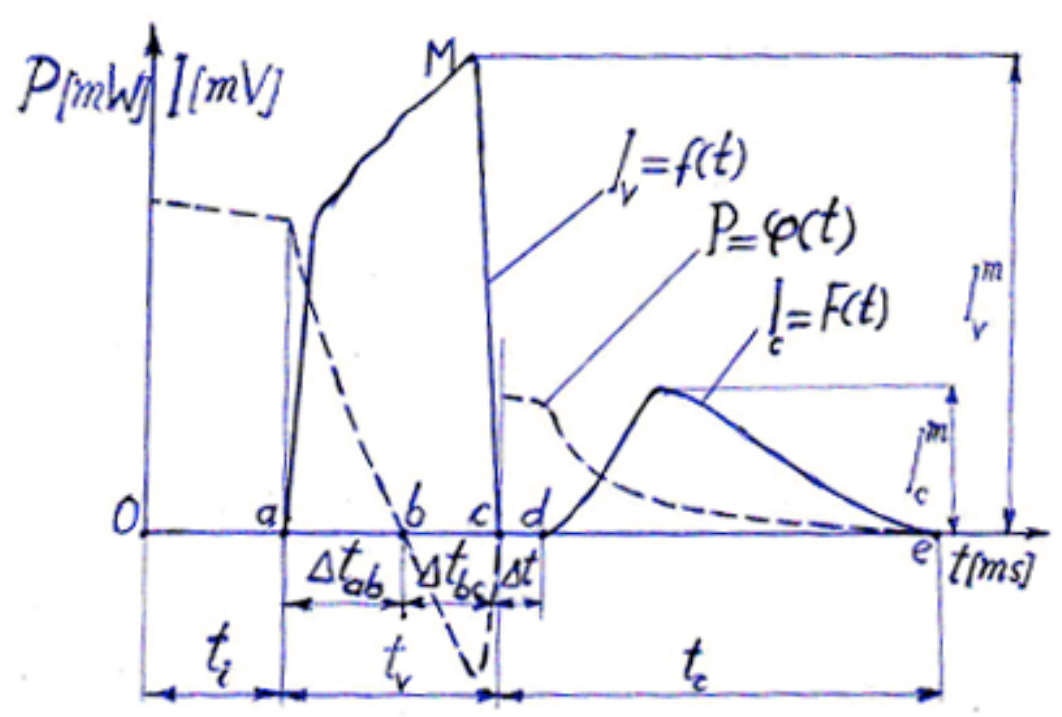

Fig. 2. Variation of the thermal power $P$ and radiation intensity $I$, during ignition and combustion into the incandescent mini-furnace of a simulator, for an IFo droplet.

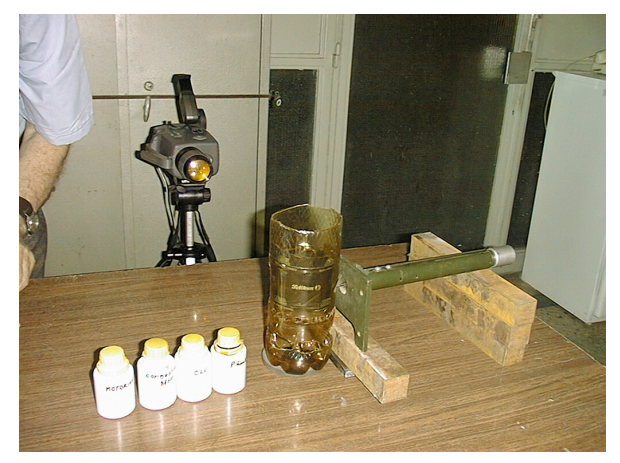


http://dx.doi.org/10.21611/qirt.2006.006

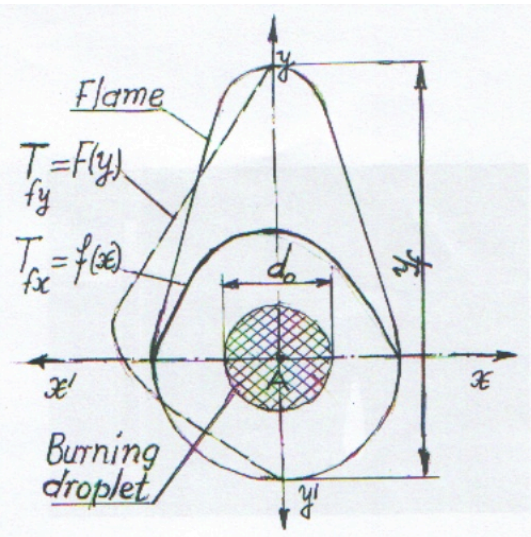

Fig. 3. Combustion simulator using an infrared camera and flame detail for schematically representation at DFMV of a superior GO

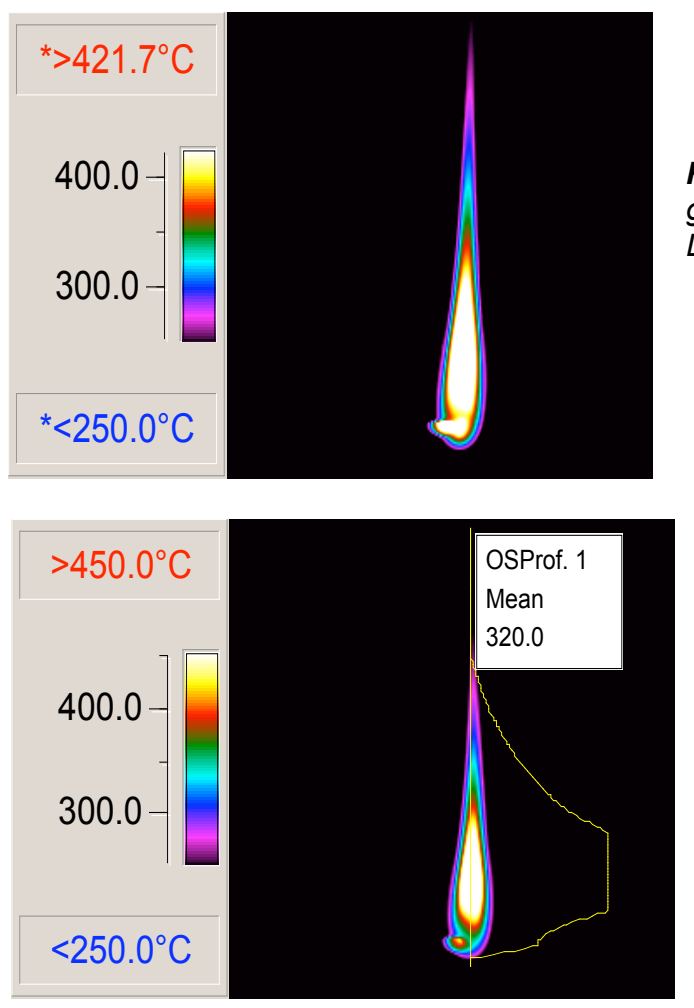

Fig. 4. IR thermogram for a superior gas oil droplet heaving $d_{0}=2 \mathrm{~mm}$, at DFMV.

Fig. 5. IR thermogram for a type of IFO $\left(d_{0}=2 \mathrm{~mm}, \quad T_{e}=T_{0}=\right.$ 295K) with representation of $T_{\text {fy }}=F(y)$, at DFMV. 
http://dx.doi.org/10.21611/qirt.2006.006

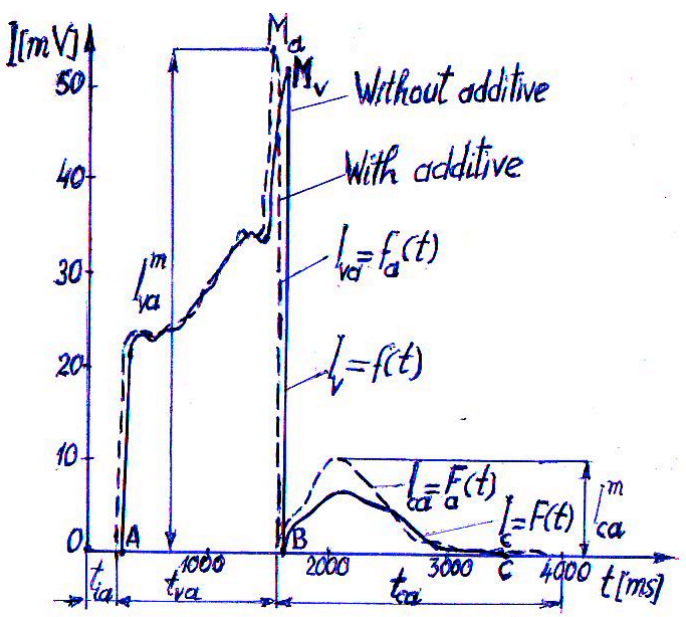

Fig. 6 COS for an lIFo droplet burned at initial conditions $T_{f i}=1023 \mathrm{~K}$, $T_{0}=300 \mathrm{~K}, T_{e}=293 \mathrm{~K}, d_{0}=1.8 \mathrm{~mm}, R e=135$, with and without additive 